Article

\title{
Long-Term Temporal Analysis of Psychoacoustic Parameters of the Acoustic Environment in a University Campus Using a Wireless Acoustic Sensor Network
}

\author{
José Montoya-Belmonte $(\mathbb{D}$ and Juan M. Navarro *(D) \\ Research Group in Advanced Telecommunications (GRITA), Universidad Católica de Murcia (UCAM), \\ 30107 Guadalupe, Spain; jmontoya3@alu.ucam.edu \\ * Correspondence: jmnavarro@ucam.edu
}

Received: 22 June 2020; Accepted: 26 August 2020; Published: 9 September 2020

check for updates

\begin{abstract}
Higher education institution campuses have been growing in size to become small cities that encompass all the infrastructures and offer many services to the university community. In order to achieve sustainable growth, it is necessary to take into account different environmental aspects, including the acoustic environment. In this paper, the application of a wireless acoustic sensor network is proposed for the long-term analysis of psychoacoustic parameters of the acoustic environment in a university campus. A network of acoustic nodes is designed and four nodes are deployed at both indoor and outdoor locations of the campus for environmental noise monitoring. A measurement campaign has been running continuously for nine months, including three months in which the state of emergency due to COVID-19 pandemic was established and the university switched to online classes. Acquired and stored data include not only the basic sound level parameters, e.g., equivalent or percentile sound pressure levels, but also psychoacoustic parameters, that are more related with noise assessment of the environment, e.g., loudness or sharpness sound levels. After analysing the acoustic environment of the campus through the complete set of nodes, results show two zones with higher noise indicators where some action plan should be developed. A detailed analysis of the temporal evolution of noise levels in these acoustically saturated zones is done, comparing values between a period of regular activity and the period of state of emergency. Different frequency distributions of sound levels are detected between day and evening periods providing a better insight into the noise sources. The results also show that binaural psychoacoustic annoyance values are correlated with loudness values in these locations, however sharpness values have minor effects.
\end{abstract}

Keywords: higher education institution; long-term acoustic measurements; wireless acoustic sensor networks; noise annoyance; acoustic sustainability

\section{Introduction}

Exposed to a mixture of environmental pollutants [1], population that lives in large cities is in a constant loss of quality of life. This combination of pollutants has an impact on the sustainability of cities in three important factors: economic, social and environmental [2]. Urban areas population will continue significantly growing [3], thus environmental sustainability is becoming a relevant piece in the development of the cities of the future or smart cities. Within the environmental factor, one of the least studied field is acoustical sustainability, together with the harmful effects of noise sources and how to monitor them $[4,5]$. 
Nowadays, city planners are working on the creation of sustainable cities trying to achieve cities with low to zero carbon emissions, build sustainable infrastructures and promote Higher Education Institutions (HEI), where sustainability practices are embedded in their curricula and facilities. Moreover, acoustic environment and noise pollution are considered a concern related with health and well-being of living environments in cities [6]. As part of the cities, university campuses and HEI facilities are experiencing a significant growth in size. HEI infrastructures can be considered as an urban area with almost the same requirements and activities than a small size city. Therefore, it is also important to take into account the quality of life of the university community and the need to improve their sustainability.

Sustainability in university campuses has been a research field of interest during last years. Universities should assume a leading role in sustainability issues in their direct activities such as classroom, laboratories, catering, offices ... According to Velazquez et al. [7], a HEI is sustainable when promotes, involves and addresses the minimization of negative environmental, social, economic and health effects. Therefore, a sustainable campus should be environmentally healthy, where waste reduction, energy and resource conservation generate a prosperous economy, along with an efficient environmental management, exporting these values to the society [8]. Mainly, HEI have two missions regarding sustainability [9]:

- To provide students new skills and competences to generate a more sustainable society.

- To reduce the environmental impact created by campus activities.

Although environmental sustainability is a topic that is usually mentioned in the literature, acoustic environment and noise pollution are overridden in most of them. In the surveys developed by Lozano et al. $[10,11]$, seven different themes were proposed in their study of HEI's sustainability, where energy and waste management are highlighted to be taken into account, but actions about acoustic environment were not enunciated. Moreover, a recent research [12] showed that new HEI designs are mostly focused on technical and economic issues whereas environment factors like global warming and social factor such as noise are ignored. In another work [13], indoor and outdoor air quality are identified as key environmental domains, however noise pollution related with transportation is only cited. Regarding social responsibility practices for HEI, a recent analysis [14] recommends the development of noise maps per building and the proposal of some actions to reduce the sound levels if needed. However, these practices related to noise obtained the lowest score in the environmental field in a research survey carried out in Spanish universities [15]. Therefore, although it is observed that within the environmental management in HEI, acoustic environment and noise pollution should be present in the sustainability studies, there is still a lack of proposals and actions to control them. In this paper, the application of a wireless acoustic sensor network (WASN), see Section 2 for related works, is proposed for the long-term analysis of psychoacoustic parameters of the acoustic environment in HEI.

Disturbance generated by noise sources and its consequences for the quality of life and health, both physical and mental are of major concern in urban environments [16]. Main sources of noise pollution are high volumes of road traffic [17] and human activities in building areas [18]. Most works in the literature are focused on evaluating noise pollution in urban environments, such as cities [19], and transportation systems [20]. However, there are also some publications that explore the acoustic environment in university campuses, because the quality of life and the academic performance of students could be influenced by this factor. According to Tristán Hernández et al. [21], the main source of noise is the one generated by the students themselves in their daily activities and it is usually amplified in areas with non-existent acoustic treatment such as common rooms and corridors. Different investigations have been developed in university facilities such as classroom room-acoustics and insulation [22], noise annoyance in staff offices and departments [23], together with a comparative study related with noise at two university campus [24]. However, in most of these previous works, noise annoyance is a parameter commonly evaluated with objective sound indicators, such as the 
equivalent sound pressure level, measuring sound energy which is a physical descriptor. Moreover, it is important to note that approximately only $30 \%$ of noise annoyance is due to physical aspects [25] thus, subjective methods and psychoacoustic parameters should be taken into consideration [21]. The acoustic nodes deployed in this work are able to calculate not only basic sound level parameters, but also binaural psychoacoustic parameters on-board, see Section 3.3 for details.

Therefore, this paper is focused on evaluating the suitability of applying a WASN-based system for long-term temporal monitoring of psychoacoustic parameters in order to assess the acoustic environment in a HEI campus. Psychoacoustic parameters are introduced in the analysis, because they can provide valuable subjective information when measuring noise annoyance. Moreover, the long-term measurement campaign allows us to study and compare the temporal evolution of the acoustic environment for different time periods. For this purpose, a WASN is designed and deployed at indoor and outdoor locations all over a university campus to carry out a long-term temporal measurement campaign. The acoustic nodes deployed can calculate both basic sound level parameters and also binaural psychoacoustic parameters on-board, and then, they send data to a software platform for storing and post-processing. In order to validate this technological system as a useful tool for acoustic environment management in HEI, several use cases are presented. The measurement campaign was nine months long and encompassed a period of regular activity and a period of state of emergency due to COVID-19 pandemic in which the university switched to online classes but keeping some of the administrative and maintenance services active. This latter period is not as strict as lock-down, and it can be a good reference for periods of low activity, i.e., without students, where the acoustic environment is quieter. First, an analysis of the obtained data of all the devices as a whole is presented, Then, a detailed analysis of the temporal evolution of noise levels at two locations, one indoor and one outdoor, is discussed.

This paper is organised into the following sections. After this introduction, a review of the state of the art of wireless acoustic sensor networks for noise monitoring is presented in Section 2. Section 3 describes materials and methods applied in the measurement campaign. In next Section 4, results obtained from the monitoring campaigns are shown and discussed. Finally, Section 5 provides the primary conclusions of this research and proposes future work.

\section{Wireless Acoustic Sensor Networks Related Works}

In this section, related works with the use of wireless acoustic sensor networks dedicated to environmental noise monitoring in urban areas are described. Then, the advantages and drawbacks of the application of WASN in university campuses are enunciated.

Smart city is an innovation in urban planning, based on the continuous learning of urban developments [26]. Along with the concept of Smart Cities, remote monitoring of environmental parameters is increasing their presence in society, being one of the scientific fields with a great evolution over last decade. This has led to the emergence of new tools for the management and evaluation of environmental pollution with the help of the advances in sensors and communications technologies [27].

Wireless sensor networks are one of these innovative tools which have been developed for monitoring the environment, capturing data with a high quality and an affordable cost for urban areas managers [28]. A wireless acoustic sensor network is composed of a set of nodes [29] which are deployed in the area of interest to continuously monitor, collect and analyze acoustic parameters values for long periods of time. WASNs can be classified in two categories depending on their nodes spatial location: fixed [23] or mobile [30] stations, that includes the mobile participatory measurement networks like smartphones. Wireless communication technologies add to the devices an ease of deployment and the ability to capture data in near real-time, store and obtain big data statistics [31] and also create dynamic noise maps [32]. Moreover, long-term monitoring of sources of noise pollution is important for the understanding of how these sounds evolve with time, in order to control and prevent them [29]. 
During the last years, WASNs have been deployed in several urban environments. New York city is monitoring the urban noise at outdoor locations, through Sound of New York City (SONYC) project with more than 50 low-cost acoustic nodes which capture both sound pressure level values and classify sound sources from the audio data [33]. Dynamap, is an european WASN-based project with pilots deployed in cities such as Roma and Milan, Italy. It aims at giving a real picture of the noise generated by vehicular traffic [34]. To this purpose, a dedicated device and software platform were developed to elaborate the information from distributed noise monitoring stations and to carry out a dynamic noise mapping system able to detect and represent in real time the acoustic impact due to road infrastructures [35]. In the region of Paris, France, different versions of an acoustic node were developed within the Bruitparif project [36] focusing on the development of assessment actions to mitigate noise and communicate the information about the soundscape to citizens and authorities [37].

Other cities involved citizens to install noise sensors located on private houses [38] or using mobile phones [39]. The use of mobile phones as an acoustic node is recently on the rise. A mobile phone can be a simple and good alternative for short term measurements, however they present drawbacks for long term measurements like power consumption and restricted processing capabilities [40]. Moreover, depending on the model and the operating system of the mobile phone, accuracy and reliability of the measurements vary [41].

There are also some researches which are focused in evaluating road traffic noise as the most important noise source in a city [34,42]. Finally, some works study the environmental noise with WASN in special urban areas, such as industrial and residential areas [43].

The advantages and drawbacks of using WASN for environmental acoustic evaluation can be summarized as follows:

- Nodes can be designed to capture sound with adequate quality for acoustic measurements and an affordable cost.

- The wireless communications of the nodes provide the network with an easy and fast deployment.

- Storing data in a cloud-based platform in near real time can help managers make early decisions [31].

- Although the nodes can be controlled and monitored remotely [44], periodic maintenance is required on site.

- WASN can be a good tool to make large-scale and long-term measurements [4], but some devices can have limitation when computing complex calculation, such as advanced acoustic parameters. However, these computing limitations can be overcome with on-edge computing, machine learning algorithms and improved features of future devices [45].

- Although achieving a high density of deployed equipment can be very costly, spatial interpolation techniques can be applied to estimate values in other locations [46].

In the revision of the state of the art, the application of WASN is a promising topic wherein there are still few publications that use their advantages to carry out noise assessments at HEI. In Ref. [47], smartphones were used to calculate sound pressure levels in several outdoor location of a campus. Whereas, a network of fixed nodes based on commercial sound level meters was deployed to monitor road traffic density and noise at the entrances of a campus in Ref. [48]. Recently, the same authors of this current work presented a short measurement campaign in which the potential of the application of WASN at university buildings was shown [23].

\section{Materials and Methods}

In this section, the characteristics of the deployed acoustic sensor network are firstly introduced. Then, a brief description of the campus and the location of the installed nodes is done. Finally, the performed measurement campaign is detailed. 


\subsection{Wireless Acoustic Sensor Network Description}

This smart campus project consists in the design and deployment of a set of wireless acoustic nodes in several locations, both outdoor and indoor, to create a network able to collect valuable data during a long period of time. This complete system includes the hardware of the nodes to capture the sound signal, the software of the nodes to process the audio signal and compute the acoustic parameters, the network topology and protocol design, and the integration with a cloud software platform to develop dashboards in order to manage devices, calculate statistical data and to show valuable information.

The acoustic nodes are electronic devices that mainly capture sound signal using a microphones linear array to evaluate the acoustic field in different environments. Moreover, the nodes also incorporate other complementary environmental sensors: a DHT 22 for temperature and humidity, and a TSL 2561 for luminosity, which can give additional information during the data analysis. As is shown in the diagram in Figure 1, each node is connected to a private WiFi network that allow them to send data to a central node. This on-the-edge node can performs as a pre-processor to store and calculate local data and also as a gateway to route the data frame to a cloud server, that runs a software platform, using a secure Ethernet connectivity. Since data is sampled and sent to the software platform once a minute, the amount of data created requires efficient techniques for its analysis both in the device and in the server. Data collected by acoustic nodes are transmitted via HTTPS communications protocols. Moreover, the access to each node through Secure Shell (SSH) is allowed, to remote control and maintenance of the network, the server and the nodes. Thanks to the developed cloud software platform, a screenshot is shown at upper layer in Figure 1, the data can be consulted and analyzed accessing to several web-based application dashboards.

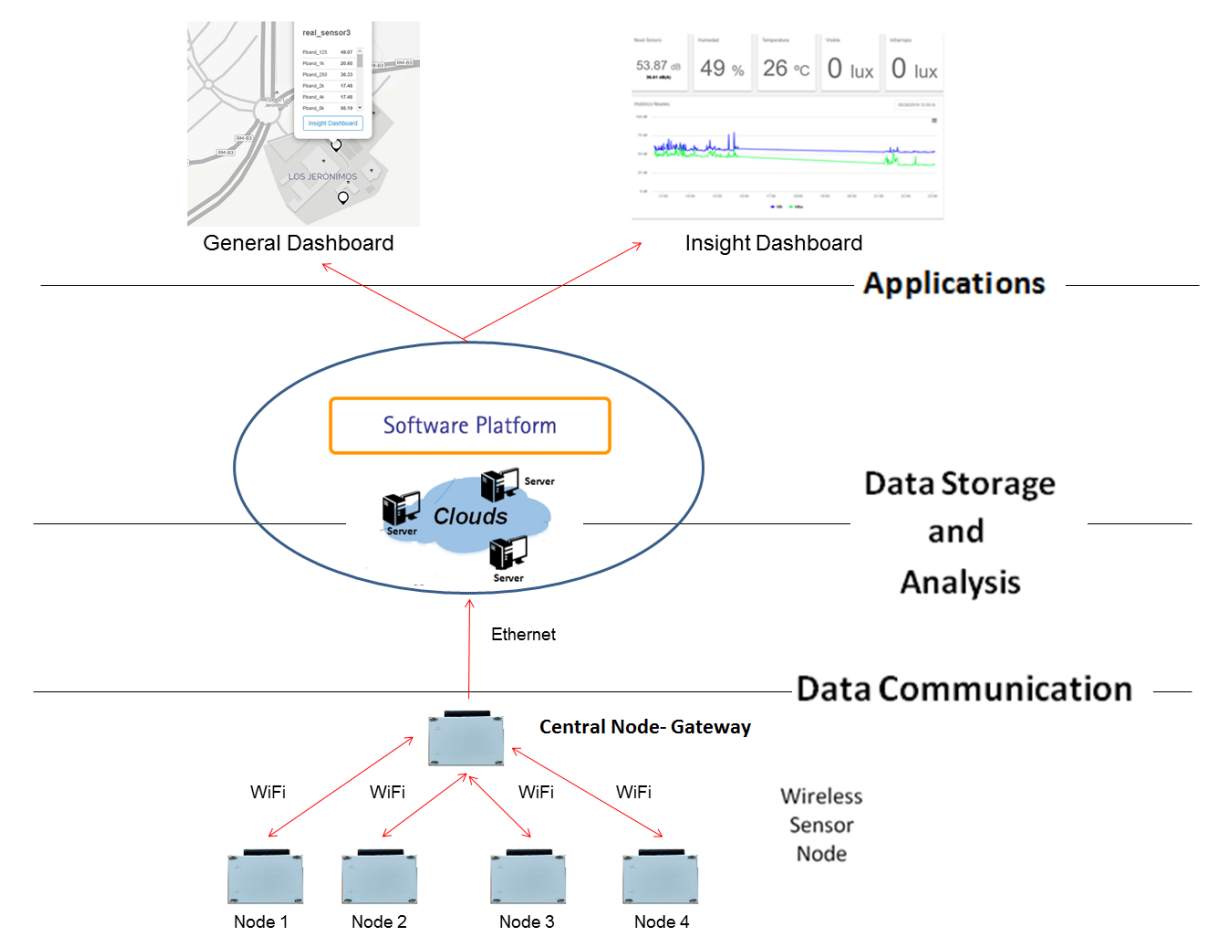

Figure 1. Architecture of environmental noise monitoring system and software applications.

This low-cost acoustic device is capable of capturing sound through the microphones array to subsequently synthesize the human binaural response with the objective of calculating on-board basic acoustic and psychoacoustic parameters values [29] which are described in the following Section 3.3. Table 1 shows the price range of the low-cost components per device used in this study. The sound acquisition and processing system, shown in Figure 2A, is composed by a processor based on the Raspberry Pi 3 model B platform and the Sony PSEye camera. The Raspberry Pi platform is the 
main core of the system and has been chosen due to its high versatility and feasibility to implement required algorithms using a well-known programming language as Python [49]. Sony PSEye has a 4-microphones linear array integrated into it, however in the designed device only the two outermost microphones are used for capturing sound and computing binaural audio signals. The device has the following main characteristics:

- Each channel is capable of processing 16-bit samples at a sampling rate of $16 \mathrm{KHz}$.

- Signal-to-noise ratio of $90 \mathrm{~dB}$.

- Power consumption of $500 \mathrm{mAh}$.

- Dynamic range of $60 \mathrm{~dB}$.

- Linear level response between 35 and $95 \mathrm{~dB}$.

- Distance between the outermost microphones is approximately 62 millimeters.

Table 1. Cost of the acoustic node.

\begin{tabular}{ccc}
\hline Component & Description & Price \\
\hline Main Board & Raspberry Pi 3 Model B & $40 \$$ \\
Microphone Array & Sony Playstation 3 Eye Camara Eyetoy & $30 \$$ \\
Power Supply & Mini UPS DL181 & $15 \$$ \\
Temperature and Humidity Sensor & DHT 22 & $10 \$$ \\
Luminosity Sensor & TSL 2561 & $5 \$$ \\
Enclosure & $150 \mathrm{~mm} \times 200 \mathrm{~mm} \times 85 \mathrm{~mm}$ with IP67 & $15 \$$ \\
Consumables & cable and connectors & $10 \$$ \\
\hline Total price per node & & $125 \$$ \\
\hline
\end{tabular}

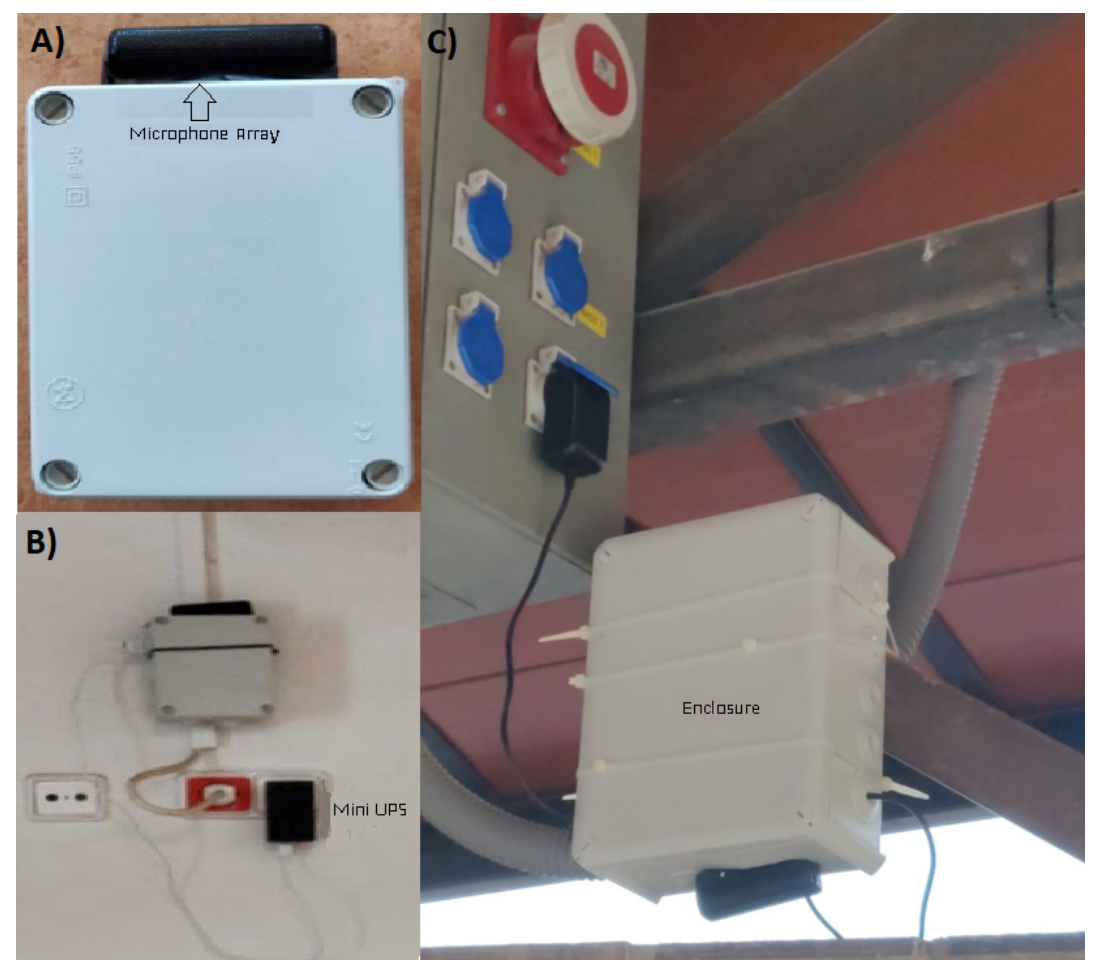

Figure 2. Detail pictures of the deployed devices. (A) External appearance of the device. Raspberry Pi and the other components are inside a protected box. At the upper part of the box, microphone array can be observed, (B) installation of the device (indoor), (C) installation of the device (outdoor).

During the development of this WASN, it was a design objective that the device had to be able of carrying out continuous monitoring for a long-term, where both WiFi and power supply failures can be 
a problem. To avoid peaks and short-time power outages, the device has been equipped with a small uninterruptible power supply that allows to maintain it working until the restoration of the power supply or to do a safely shut down of the device if 10-minutes cut-off time is exceeded. Moreover, central node runs a program that periodically monitors the status of the WiFi network and the other nodes, sending reports and alerts via email to the WASN administrator.

\subsection{Distribution of Sensor Nodes}

University campus is located in the middle of an agricultural area in the surroundings of the city of Murcia (Spain). University is composed of different and very diverse facilities, from indoor areas such as a library, dining rooms, pavilions with classrooms, offices and laboratories, to the outdoor areas such as seating areas. This HEI has been built around a historical monastery with modern infrastructures in constant renovation. Each of these spaces has it own soundscape caused by the following noise source categories: natural, anthropological and technological [50]. For instance, in the classrooms main noise source is the students themselves, but in reprography room there is also noise contribution from the photocopying machines. Around 20,000 people coexist in the environment of the university, including students, teachers, administrative staff and other workers, in an age range of 18 and 65 year old. A general map of the campus with the points of installation of the different nodes is shown in Figure 3.

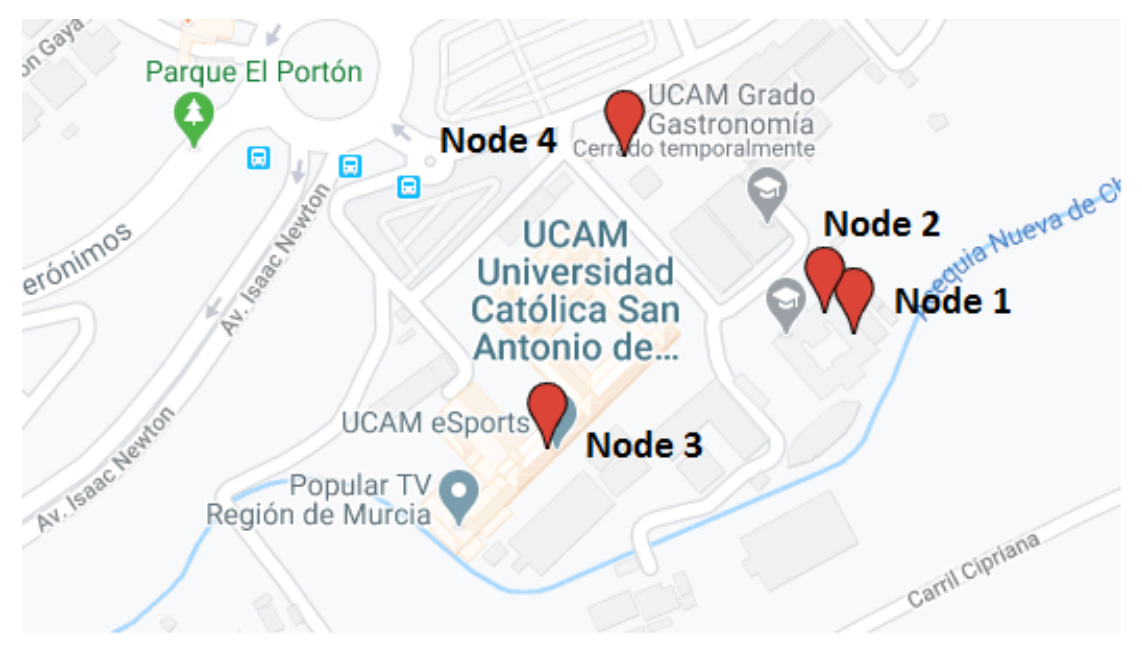

Figure 3. Location long-term measuring points.

In Table 2, the set of nodes are listed with a description of their location. These locations have been chosen in order to cover different acoustic environments. For this work, sensor nodes were located both in indoor or outdoor areas. The outdoor zone is a crowded place where staffs and students can use in break times and to hold special activities like forums and exhibitions. Therefore, it is a place where any member of university community can participate and the noise source is mostly anthropological. A detail of the node 4 installation is shown in Figure 2C. The rest of nodes are indoors, in particular, an office, a classroom and an entrance hall. A detail of the node 2 installation is shown in Figure 2B. All nodes were installed complying the recommendations by Spanish regulation E.C. 49/2002 [51] and ISO 1996-2:2017 [52] related with placement of devices and possible corrections.

Table 2. List of deployed nodes with a description of their location.

\begin{tabular}{ccc}
\hline Node & Facility & Location \\
\hline 1 & Office & Indoor \\
2 & Classroom & Indoor \\
3 & Entrance Hall & Indoor \\
4 & Seating Area & Outdoor \\
\hline
\end{tabular}




\subsection{Measurement Campaign Description}

In this work, data captured from a measurement campaign is used to show use cases of applying a WASN-based system for long-term temporal monitoring of psychoacoustic parameters to evaluate the acoustic environment in the locations described in previous section. The deployed WASN is working from September 2019 and the measurement campaign for this work is nine months long. It is important to note that during part of this campaign, the COVID-19 pandemic spread, thus the state of emergency was established. During this period of time, the university switched to online classes, however some critical services, e.g., administrative and maintenance services, remain active. The acoustic node is able of calculation basic and psychoacoustic parameters. In the following, a description of these indices is presented.

The main parameter to measure sound and noise levels is the sound pressure level, denoted as $L_{p}$ and units in decibels $(\mathrm{dB})$. To obtain $L_{p}$, a logarithmic value of the root mean square instantaneous pressure of a sound relative to a reference value is calculated,

$$
L_{p}=20 \cdot \log \frac{p}{p_{0}}
$$

where $p_{0}$ is the reference sound pressure which value is $20 \mu \mathrm{Pa}$ [52] and $p$ is the instantaneous sound pressure of the sound signal at the time of measurement.

The parameter $L_{p}$ is usually measured over a given time period $T$ to quantify the noise environment on a single value using the equivalent sound pressure level, denoted as $L_{e q, T}$ [52],

$$
L_{e q, T}=10 \cdot \log \frac{1}{T} \int_{t_{1}}^{t_{2}} \frac{p}{p_{0}} d t
$$

where $T=t_{2}-t_{1}$.

Sound pressure is acquired by our acoustic nodes on a continuous basis with a time period of 1-min, denoted as $L_{e q, 1 m}$ in $\mathrm{dB}$ units. They are also able to calculate it in A frequency-weighting, denoted as $L_{e q A, 1 m}$ in dBA units, which is a first effort to account for the relative loudness perceived by the human ear [53]. Afterwards, devices send the obtained values to the software platform to be stored and so that statistical analysis can be processed.

In this work, sound pressure level results are sometimes presented applying a long-term average of $L_{e q, 1 m}$ or $L_{e q A, 1 m}$. Different time periods $T$ can be defined, for instance it is denoted as $L_{e q, 1 D}$ for a 24-h day period and $L_{e q, 1 h}$ for a 60 -min period. These values are calculated using an energetic average with the following equation [52],

$$
L_{e q, T}=10 \cdot \log \frac{1}{n} \sum_{i=1}^{n} 10^{\frac{L e q_{i}}{10}},
$$

where $n$ is the total number of 1-minute intervals and $L_{e q}$ is the equivalent sound pressure level in the interval $i$ obtained by the sensor applying Equation (2). For instance, to calculate $L_{\text {eq, }, 1 h}, 60$ values of $L_{e q, 1 m}$ are averaged.

Moreover, to better correlates effects of noise on people, subjective parameters calculation has been implemented in the acoustic nodes obtaining binaural psychoacoustic annoyance values extending the monaural Zwicker's model [53]. A simplified Zwicker's model is followed due to the stability of the sound sources in this environment [23]. Therefore, to obtain binaural psychoacoustic annoyance, binaural loudness, denoted as $N_{\text {binaural }}$ from Nuisance, and binaural sharpness, denoted as $S_{\text {binaural }}$, are previously calculated in the acoustic node.

Standardized in ISO 532B [54], loudness is the subjective intensity of sound, being a psychological correlate of the amplitude of a sound, from quiet sounds to loud sounds. Therefore, loudness can be defined as a perceptual measure of the intensity perceived by human ear, where sones is its unit of measurement. As stated above in Section 3.1, the acoustic node synthesizes the human binaural 
response estimating two audio signals, each one corresponding to one ear [29]. From these signals, the total monaural loudness of a sound reaching the ear, either left $N_{\text {Left }}$ or right $N_{\text {Right }}$, is calculated by integrating loudness values in each of the 24 critical Bark band-specific, denoted by $z$, for all frequency contributions, [54]

$$
N=\int_{0}^{24 B A R K} N^{\prime}(z) d z
$$

where $N^{\prime}(z)$ is a specific loudness per Bark band $z$. Each $N^{\prime}(z)$ is previously calculated according to

$$
N^{\prime}(z)=0.08\left(\frac{E_{\text {thq }}}{E_{0}}\right)^{0.23} \cdot\left[\left(0.5+0.5 \cdot \frac{E_{\text {sig }}}{E_{\text {thq }}}\right)^{0.23}-1\right] \frac{\text { Sone }}{\text { Bark }}
$$

where $E_{0}$ is the excitation that corresponds to the reference intensity $I_{0}=10^{-12} \mathrm{~W} / \mathrm{m}^{2}, E_{\text {thq }}$ is the equal level loudness contour at the hearing threshold and $E_{\text {sig }}$ corresponds to the excitation pattern of each of the signals of the stimuli $\left(E_{\text {Left }}\right.$ and $\left.E_{\text {Right }}\right)$, read References $[53,54]$ for details of these signals.

After calculation of $N_{\text {Left }}$ and $N_{\text {Right }}$ with Equation (4), the formula applied to obtain the binaural loudness is enunciated as [55],

$$
N_{\text {binaural }}=0.75 \cdot N_{\text {Left }}+0.75 \cdot N_{\text {Right }} .
$$

Sharpness is defined as the value of sensory human perception of unpleasantness in sounds produced by high frequency components. Acum is its unit of measurement. It can be calculated by using the following equation [53],

$$
S=0.11 \frac{\int_{0}^{24 B A R K} N^{\prime}(z) \cdot g(z) \cdot z \cdot d z}{\int_{0}^{24 B A R K} N^{\prime}(z) \cdot d z}
$$

where for Bark bands $z<14$, i.e., low frequency bands, $g(z)=1$ and for Bark bands $z \geq 14$, i.e., high frequency bands, a weighting function $g(z)=0.00012 \cdot z^{4}-0.00056 \cdot z^{3}+0.1 \cdot z^{2}-0.81 \cdot z+3.51$ is applied. $N^{\prime}(z)$ is again the specific loudness per band calculated with Equation (5).

Following the same procedure as that applied with loudness, binaural sharpness can be the calculated using [55],

$$
S_{\text {binaural }}=0.75 \cdot S_{\text {Left }}+0.75 \cdot S_{\text {Right }} .
$$

Finally, results of binaural loudness, Equation (6), and binaural sharpness, Equation (8), are used to calculate the binaural psychoacoustic annoyance

$$
P A_{\text {binaural }}=N_{5_{\text {binaural }}} \cdot\left(1+w_{S_{\text {binaural }}}\right),
$$

where $N_{5_{\text {binaural }}}$ is the percentile 5 of binaural loudness, and $w_{S_{\text {binaural }}}$ is equal to $\left(S_{\text {binaural }}-1.75\right)$. $0.25 \log \left(N_{5_{\text {binaural }}}+10\right)$ if $S_{\text {binaural }}>1.75$, or 0 if $S_{\text {binaural }} \leq 1.75$.

Then, all these parameters are packed in a data frame and sent to the cloud server. The data can be also stored locally as a backup.

\section{Results and Discussion}

In this section, the data captured with the WASN during the measurement campaign described in previous section is analyzed and discussed. First, results from all devices are summarized to described the acoustic environment at the node locations. Then, results from measurement points with the highest annoyance level, one outdoor and one indoor, are discussed in details analyzing the temporal evolution. In the following sections, the period of ordinary activity during the academic year is called regular period and extends from 15th of January 2020 to 15th March 2020. Moreover, the period when 
the lectures become online due to COVID-19 pandemic is called state of emergency and extends from 16th of March to 15th of May 2020.

\subsection{General Results Regarding the Set of Devices}

In this first section, results about all the nodes are shown and discussed in order to describe the acoustic environment of the campus over the regular period.

Table 3 shows a summary of results for $L_{e q A}$, binaural loudness and binaural sharpness for every devices in the regular period. In this table, long-term measurement data is described using statistical parameters. AV denotes to perform Equation (3) for equivalent sound level, whereas it denotes an arithmetic average for binaural loudness and binaural sharpness. SD denotes standard deviation of the parameters during measurement period. $P_{n}$ denotes percentile values below which $n \%$ of the observations may be found. Reader should note that in acoustics, some literature define $L_{n}$ as the level exceeded for $\mathrm{n} \%$ of the time, thus for instance $L_{90}$ corresponds with $P_{10}$ in the table. Regarding $L_{e q A}$, Table 3 shows that the zone where node 3, Entrance Hall, is located, has the highest level being $52.5 \mathrm{dBA}$. This zone is one of the busiest areas of the university where most of the administrative offices are located. Moreover, the node is situated in a long corridor of the former monastery with a high ceiling that contributes a high reverberation. Second highest level, $43.9 \mathrm{dBA}$, belongs to Node 4 , the outdoor seating area that is frequented by students during rest periods. Node 1 and node 2 are the quiets zones corresponding with a lectures' office and a regular size classroom of $50 \mathrm{~m}^{2}$. Moreover, nodes with higher average values have higher standard deviation values that represent more variability in these areas. Regarding binaural loudness values, node 3 has again the highest value with 10.5 followed by node 4 with 5.8. However, binaural sharpness values are similar in all nodes showing that high frequencies are not affecting much in the loudness level and consequently in the psychoacoustic annoyance.

Table 3. Summary of statistical values for $L_{e q A}$, binaural loudness and binaural sharpness in the indoor/outdoor environment for the open period.

\begin{tabular}{lcccccccccccc}
\hline & \multicolumn{3}{c}{ Node 1 } & \multicolumn{3}{c}{ Node 2 } & \multicolumn{3}{c}{ Node 3 } & \multicolumn{3}{c}{ Node 4 } \\
\cline { 2 - 12 } & $\boldsymbol{L}_{\boldsymbol{e q}, \boldsymbol{A}}$ & $\boldsymbol{N}_{\text {binaural }}$ & $\boldsymbol{S}_{\text {binaural }}$ & $\boldsymbol{L}_{\boldsymbol{e q}, \boldsymbol{A}}$ & $\boldsymbol{N}_{\text {binaural }}$ & $\boldsymbol{S}_{\text {binaural }}$ & $\boldsymbol{L}_{\boldsymbol{e q}, \boldsymbol{A}}$ & $\boldsymbol{N}_{\text {binaural }}$ & $\boldsymbol{S}_{\text {binaural }}$ & $\boldsymbol{L}_{\boldsymbol{e q}, \boldsymbol{A}}$ & $\boldsymbol{N}_{\text {binaural }}$ & $\boldsymbol{S}_{\text {binaural }}$ \\
\hline $\mathrm{AV}$ & 37.1 & 3.3 & 1.9 & 39.9 & 4.2 & 1.6 & 52.5 & 10.5 & 1.6 & 43.9 & 5.8 & 1.7 \\
$\mathrm{SD}$ & 7.3 & 3.0 & 0.2 & 7.0 & 3.6 & 0.1 & 7.9 & 5.9 & 0.2 & 7.5 & 3.9 & 0.1 \\
$P_{5}$ & 30.5 & 1.5 & 1.6 & 34.3 & 1.9 & 1.5 & 43.7 & 4.9 & 1.4 & 35.9 & 2.6 & 1.5 \\
$P_{10}$ & 30.8 & 1.5 & 1.7 & 34.4 & 1.9 & 1.5 & 44.0 & 5.0 & 1.4 & 36.3 & 2.7 & 1.5 \\
$P_{50}$ & 33.7 & 1.8 & 2.0 & 38.1 & 3.2 & 1.6 & 51.0 & 8.7 & 1.6 & 41.6 & 4.3 & 1.6 \\
$P_{90}$ & 47.2 & 6.6 & 2.1 & 48.9 & 7.2 & 1.7 & 63.7 & 18.7 & 1.9 & 55.3 & 11.1 & 1.8 \\
$P_{\text {dif }}$ & 16.4 & 5.1 & 0.4 & 14.5 & 5.2 & 0.2 & 19.7 & 13.7 & 0.4 & 19.0 & 8.4 & 0.3 \\
\hline
\end{tabular}

The evaluation of the $P A_{\text {binaural }}$ was performed according with the method described in Section 3.3. The results are graphed in Figure $4 \mathrm{a}$ and show that the sound environment with higher value of $P A_{\text {binaural }}, 4.9$, that corresponds to the entrance hall. Just as it happened with loudness values, seating area environment is the second with higher $P A_{\text {binaural }}$, being 2.6. Finally, the lowest values of $P A_{\text {binaural }}$ correspond to the office and the classroom, resulting 1.5 and 1.9 respectively. Regarding variability of the sound environment, the observation carried out with the standard deviation is also corroborated by the percentile values that are shown in Table 3 . The difference value between $P_{90}$ and $P_{10}$, denoted as $P_{\text {dif }}$ in Table 3, is also drawn in Figure $4 \mathrm{~b}$ for each node. These percentile difference values are higher in node 3 and 4 , around $20 \mathrm{~dB}$, than in node 1 and 2, around $15 \mathrm{~dB}$. 

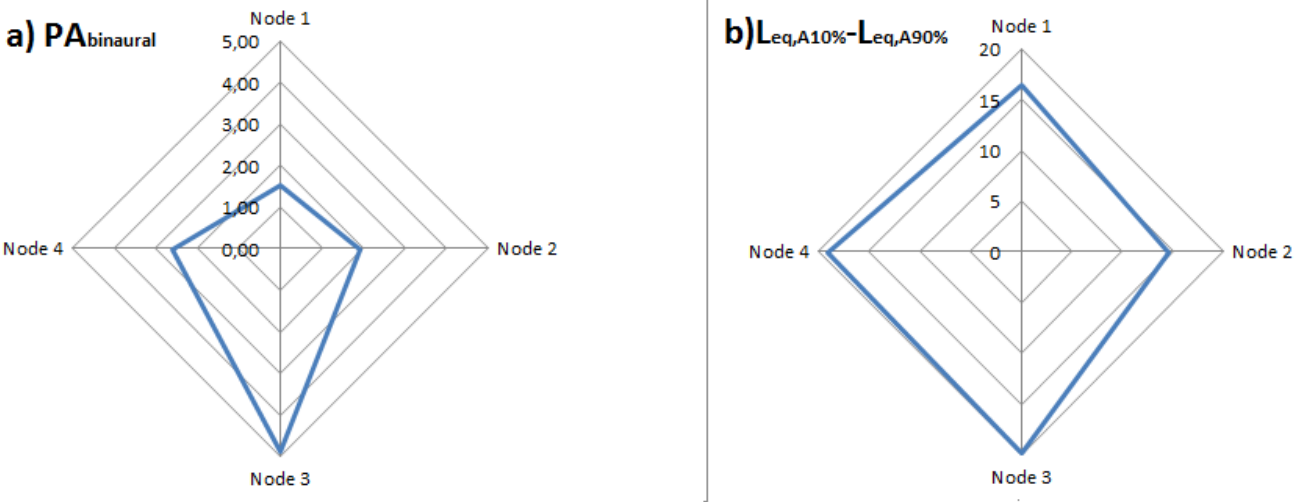

Figure 4. (a) Psychoacoustic annoyance value for each node. (b) Percentile difference value for each node.

To analyze the importance of each parameter in the annoyance, a set of radial graphs is shown in Figure 5 with the values of percentiles for binaural loudness and binaural sharpness. Node 3 values in Figure $5 \mathrm{c}$ present the higher values in $N_{\text {binauraldif }}$ and $N_{\text {binaural50 }}$ showing the relevance in a direct correlation with $P A_{\text {binaural }}$ [56]. A lower values of $N_{\text {binaural50 }}$ in node 4 is related with a lower $P A_{\text {binaural }}$. Percentile values for binaural sharpness don't show clear correlation with $P A_{\text {binaural }}$ in this case. As a recommendation to improve the acoustic sustainability of this zones, actions should be taken to decrease maximum noise levels and to create a soundscape with sound sources that present lower level variability.

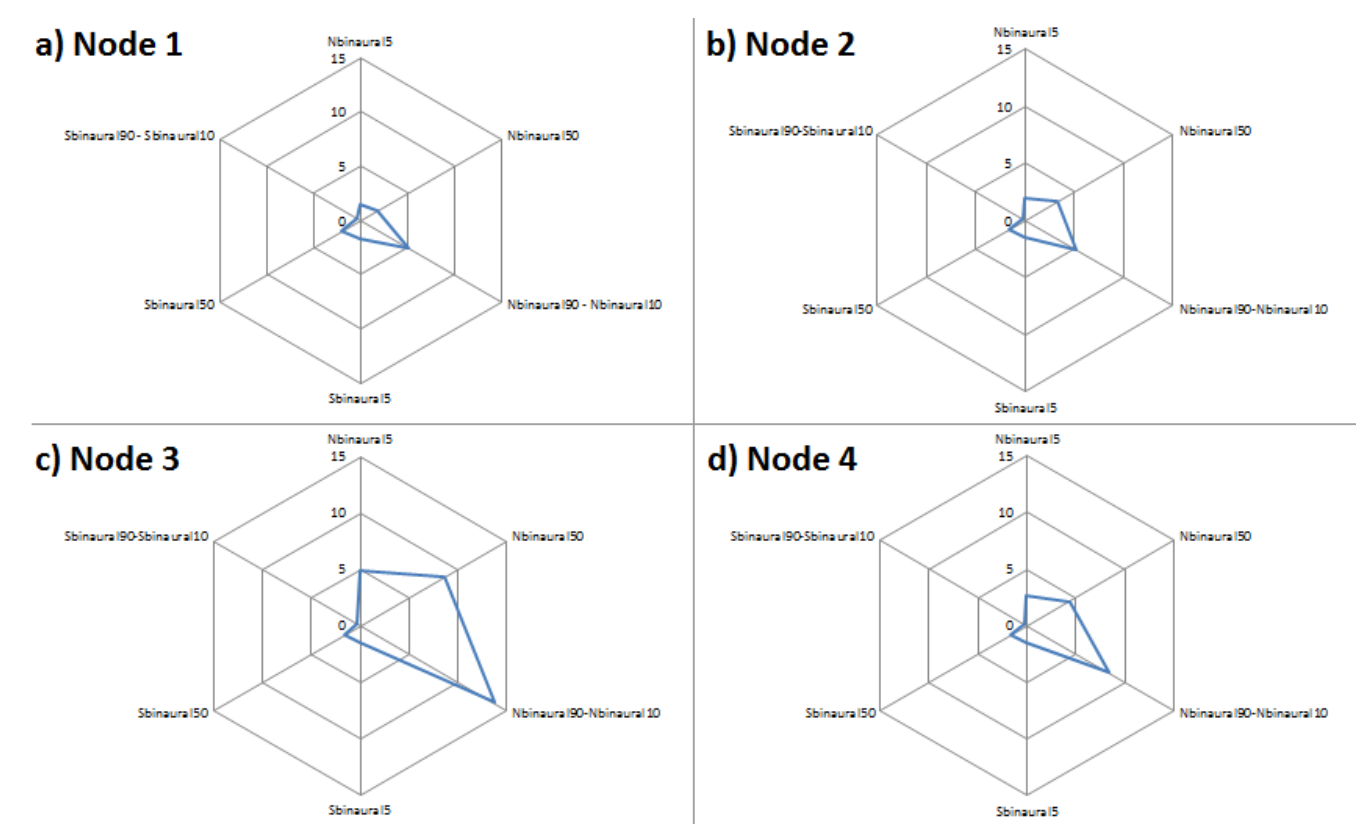

Figure 5. Psychoacoustic parameters values for each node from (a) for node 1 to (d) for node 4 . Binaural loudness percentile 5, 50 and difference 90-10, binaural sharpness percentile 5, 50 and difference 90-10.

Storing the data in a cloud-based platform allows to also perform spatial statistical analysis using an interpolation method [34]. In this study, a method based on spatial autocorrelation, Kriging [23] has been used to obtain a complete noise map of the campus. Through the ordinary Kriging technique, predictions of average values in Table 3 are calculated at different locations. Figure 6 shows several variograms representing the spatial distribution of (a) $L_{e q, A}$, (b) $N_{\text {binaural }}$, (c) $S_{\text {binaural }}$ and (d) $P A_{\text {binaural }}$. 


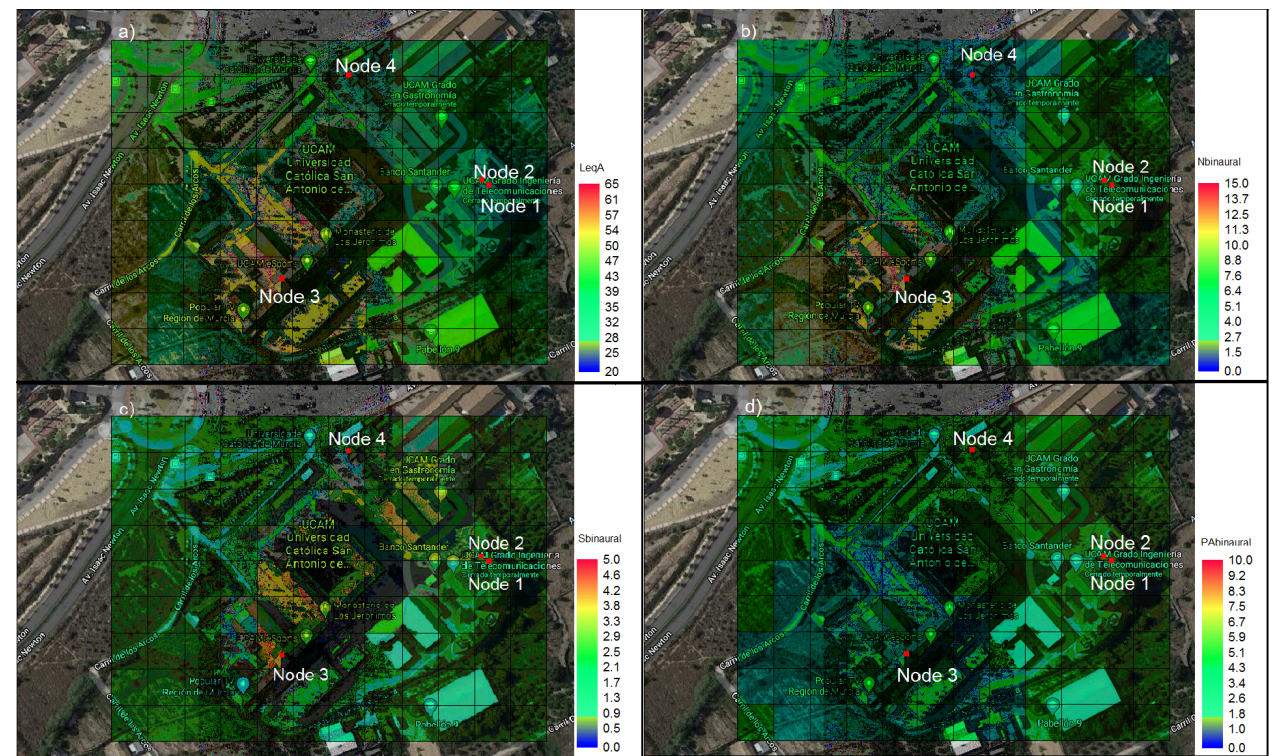

Figure 6. Noise map obtained applying Kriging spatial interpolation technique to AV values in Table 3.

(a) $L_{\text {eq, } A}$, (b) $N_{\text {binaural }}$, (c) $S_{\text {binaural }}$ and (d) $P A_{\text {binaural }}$.

\subsection{Result Regarding Node at Outdoor Area}

Next, a more in-depth study of the outdoor acoustic node 4 is presented. In this location, it can be observed the natural soundscape of the campus over a long-term measurement. First, it is graphed in Figure 7 the variation of $L_{e q A}, 1 \mathrm{~h}$ values, with an integration period of $1 \mathrm{~h}$, from 15th of March 2020 to 15th of April 2020. This graph shows the evolution of the sound pressure level during the first weeks of the state of emergency period. The first dates correspond to the beginning of emergency, being these first days a week of transit to full state of emergency. It is important to note that days 20th, 23th and 24th of March 2020 were days with heavy rain events, so a period of high noise levels appears. After those dates, a reduction in sound levels of about $10 \mathrm{~dB}$ is observed until the levels are stabilized in the state of emergency period, as it is studied in details below.

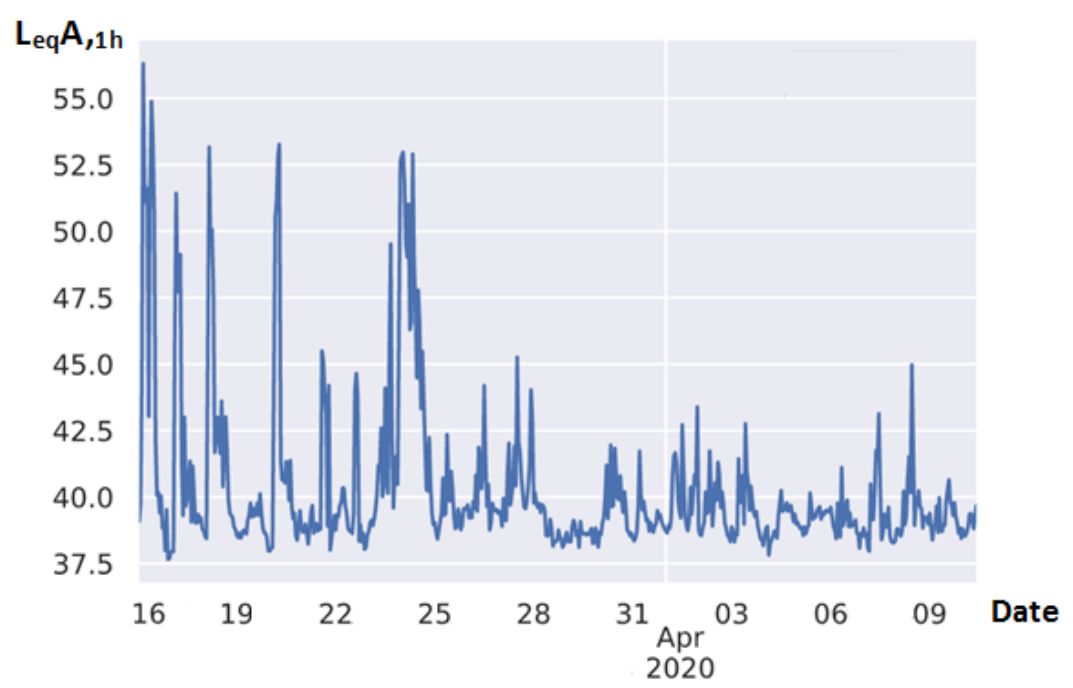

Figure 7. $L_{e q A, 1 h}$ values at node 4 during the first weeks of the state of emergency period, from 15th of March 2020 to 15th of April 2020.

To analyze the sound levels along all the state of emergency period, Figure 8 shows $L_{e q} A, 1 D$ values, with an integration period of 1 day, at node 4 from 15th of March 2020 to 15th of May 2020. 


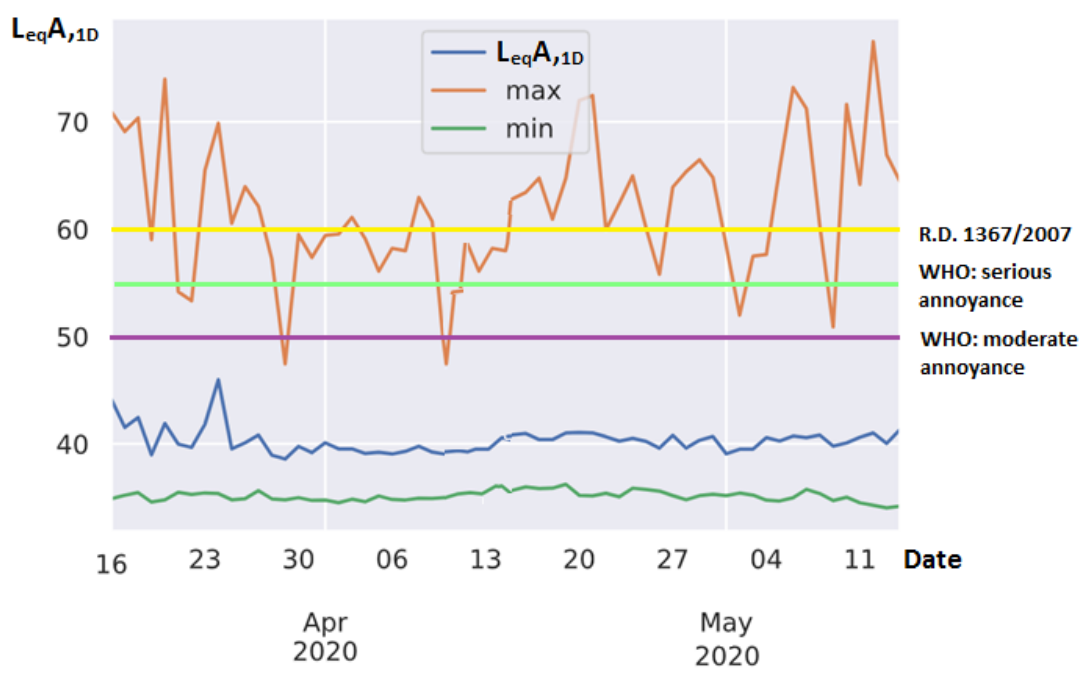

Figure 8. $L_{e q A, 1 D}$ values at node 4 during the state of emergency period, from 15th of March 2020 to 15th of May 2020.

Figure 8 shows that in $100 \%$ of the state of emergency period measuring days, the values of $L_{e q A, 1 D}$ do not exceeded the reference values according to both International organization WHO [57], that defines reference values of $50 \mathrm{dBA}$ and $55 \mathrm{dBA}$, suggesting that they can produce moderate and serious annoyance respectively, and Spanish national regulation R.D. 1367/2007 [58], that established the value of $60 \mathrm{dBA}$ for assessing the impact of outdoor noise on the population at the Education facilities. Moreover, Figure 8 also shows maximum and minimum sound pressure levels over 1 day interval. It is suggested that these maximum values correspond to tasks that are performed when there is no on-site academic activity, such as cleaning, gardening or maintenance tasks. These peaks values are produced in a punctual manner, but they are shown since once measurement is done per minute as described in Section 3.3.

A comparative analysis of the two periods, regular and state of emergency period, is then be carried out to observe the differences and to discuss the results. Figure 9 represents the histogram of $L_{e q A, 1 m}$ values for both periods. regular period histogram shows a binormal distribution with two clearly separated bell curves, one centred around $40 \mathrm{dBA}$ and other around $50 \mathrm{dBA}$. However, the state of emergency period histogram shows a narrower normal curve than open period and centred around $40 \mathrm{dBA}$, giving an idea of the effect on the acoustic environment caused by the change of lectures modality to on-line.

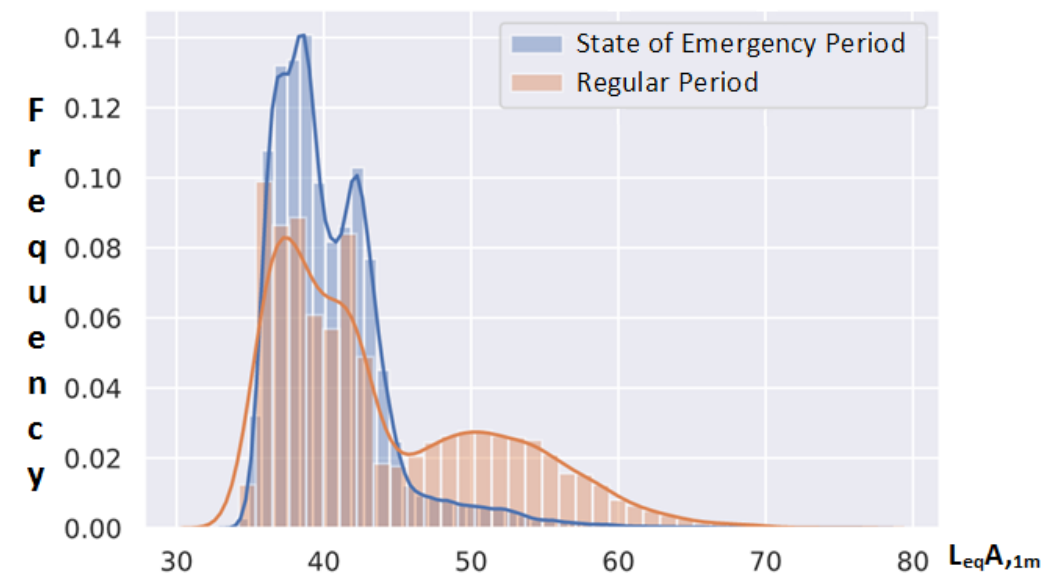

Figure 9. Frequency distribution graph of $L_{e q A, 1 m}$ values at node 4 in both closed and open period. 
In order to analyze in details the sound level distributions along a day, it has been divided the entire day in three different time intervals [51]. Long-term average noise levels are defined as: day interval corresponds from 6 to $18 \mathrm{~h}$, evening interval from 18 to $22 \mathrm{~h}$ and night interval from 22 to $6 \mathrm{~h}$. Figure 10 shows several frequency distribution graphs for both state of emergency and regular periods for the previously defined time intervals.
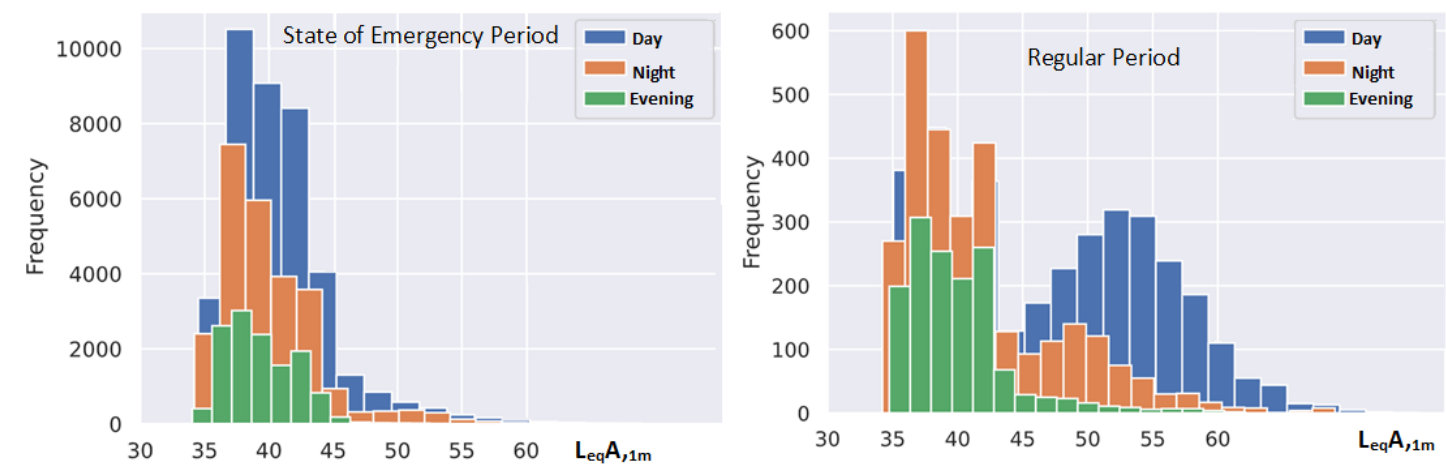

Figure 10. Frequency distribution graphs of $L_{e q A, 1 m}$ values at node 4 for day, night and evening intervals comparing state of emergency and regular periods.

As can be seen in Figure 10, night sound pressure level distributions are in the same range in both periods, which is somewhat normal, as the activity of the university is closed at night. However, evening and day distributions present noticeable differences between regular and state of emergency period observing again the second bell curve. First curve with the lower sound levels indicates the background noise of this environment, while the second curve informs about the level values of the regular sound sources that are registered at this outdoor location. This second curve is less pronounced in frequency counts in the evening interval because the activity of the University is reduced in the afternoon, but approximately $10 \mathrm{~dB}$ higher in comparison with the background noise level. While in day interval, a higher secondary frequency curve appears with a difference of approximately $15 \mathrm{~dB}$ sound pressure level higher when the university is in regular period than in state of emergency. These results confirm that optimum improvement initiatives for acoustic sustainability should be proposed for the day time interval in the outdoor environment of the campus.

\subsection{Result Regarding Node at Indoor Area}

Finally, some results regarding the indoor acoustic node 3 are presented. This location was the noisiest according to presented data in Table 3. In this case, it is of interest to analyze sound levels when the university is in regular period, because results of the state of emergency period show minimum values most of the time.

Figure 11 shows $L_{e q A, 1 D}$ values together with maximum and minimum values, with an integration period of 1 day, at node 3 during February 2020. It can be observed that $L_{e q A, 1 D}$ values are lower than $55 \mathrm{dBA}$, which is the recommended level for serious annoyance from WHO.

Again, a study of frequency distribution graphs for both state of emergency and regular periods at node 3 for the day time intervals is examined. This time, state of emergency period values in Figure 12 clearly show that there is almost no activity during all intervals with an average level value of $35 \mathrm{dBA}$. Only day interval exhibits some high sound pressure level events which are related with maintenance works. Regular period data in Figure 12 shows valuable information about the behaviour of the sound field in the different time intervals. In general, the three distributions are positive asymmetrical with an average level about $45 \mathrm{dBA}$, that represent the background noise level at this indoor location. Moreover, it is worth noting that day interval has a secondary normal curve in the range between 55 and $65 \mathrm{dBA}$, that represent the noise level of university regular activities. Therefore, the difference between background noise level and regular noise sources in the regular period could be estimated as 
$15 \mathrm{~dB}$. As previously indicated, main noise sources are students and university staff activities, so to reduce sound pressure levels an achieve values lower than $50 \mathrm{dBA}$, it can be suggested to install sound absorption materials that can decrease reverberant sound field.

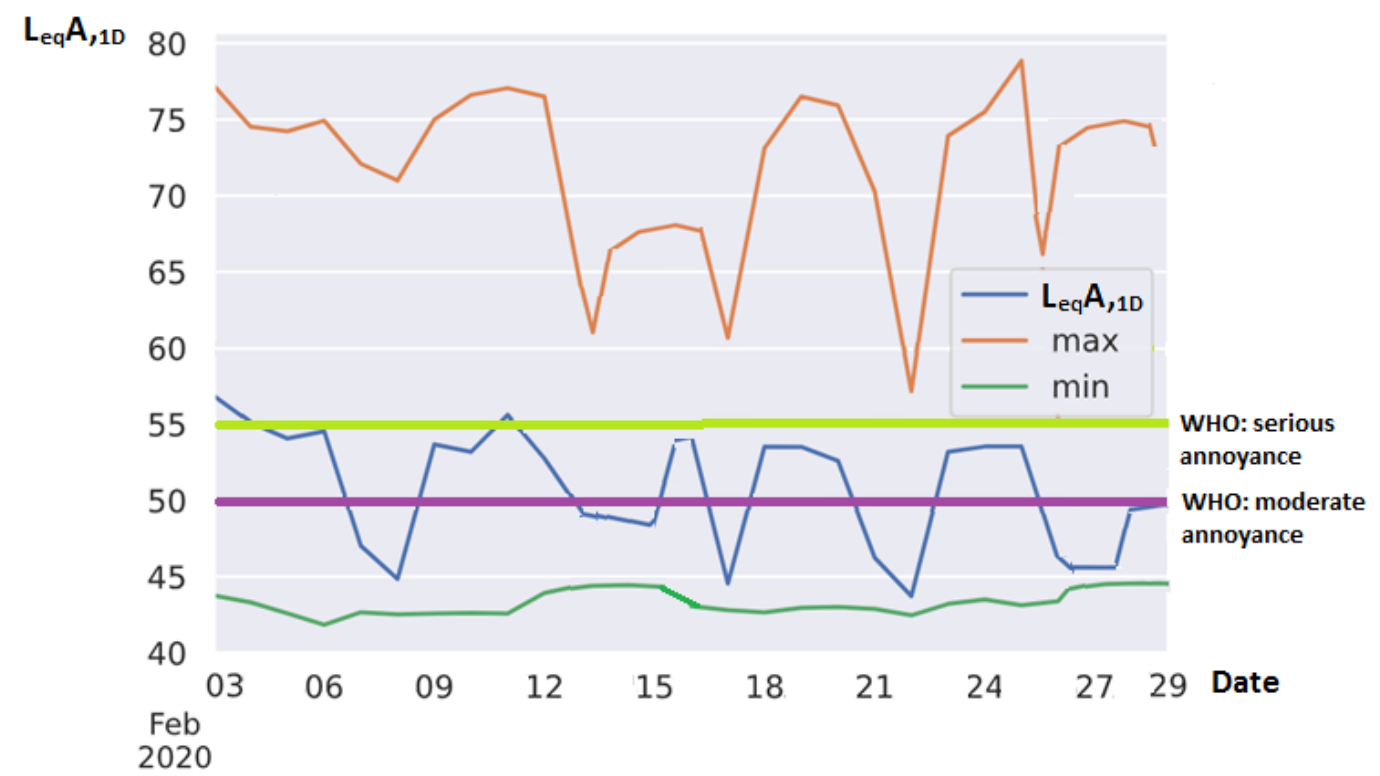

Figure 11. $L_{e q A, 1 D}$ values at node 3 during regular period, from 1 st of February 2020 to 29 th of February 2020.
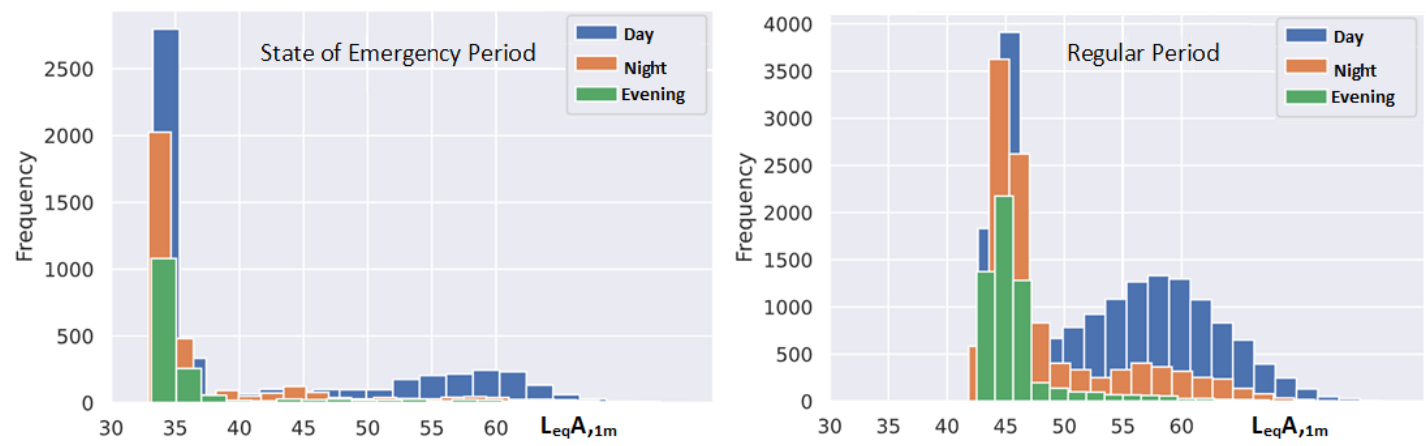

Figure 12. Frequency distribution graphs of $L_{e q A, 1 m}$ values at node 3 for day, night and evening intervals comparing state of emergency and regular periods.

In this paper, the application of a wireless acoustic sensor network is proposed for the long-term analysis of psychoacoustic parameters of the acoustic environment in a university campus.

\section{Conclusions}

In this work, the application of a wireless acoustic sensor network for the long-term analysis of psychoacoustic parameters of the acoustic environment at different locations of a higher education institution is proposed and evaluated. A WASN-based system has been designed and deployed at a university campus locating four nodes in both indoor and outdoor environment. A long-term measurement campaign of nine months has been carried out collecting and storing several acoustic parameters each minute, such as equivalent sound pressure level, loudness and sharpness. The deployed acoustic nodes allow the computation of binaural psychoacoustic parameters through Zwicker's model providing a noise annoyance assessment in humans of the acoustic environment.

The cloud-based platform has been used to compute spatio-temporal analysis of the acoustic environment. The results obtained by the wireless acoustic sensor network show that the university is 
mainly affected by noise sources during day time interval, when students and university staff develop their core tasks. However, analyzed locations currently complies with international recommendations and national regulations on noise. The entrance hall, where node 3 was placed, has the highest equivalent sound pressure level being $52.5 \mathrm{dBA}$ followed by the seating area, where the node 4 was placed, being $43.9 \mathrm{dBA}$. It has been shown that binaural psychoacoustic annoyance values are correlated with loudness values in these locations, however sharpness values have minor effects. Noise maps have been also obtained applying Kriging interpolation technique to perform spatial analysis.

Long-term measurements enable to analyze the temporal evolution of the acoustic indices. Data from nodes 3 and 4 have been analyzed in details comparing two time periods of the measurement campaign, the state of emergency period due to COVID-19 pandemic where lectures went on-line and regular academic period. Frequency distribution graphs of the equivalent sound pressure level have shown normal curves with different average between day, evening and night intervals and periods.

Although much work has to be done in order to provide accurate noise level maps using WASN, it has been shown that the proposed system presented in this work is a useful tool for environmental noise monitoring in higher education institution. Future works will focus on increasing the number of deployed devices, improving the central node to avoid data loss and provide on the edge computing features.

Author Contributions: Conceptualization, J.M.N. and J.M.-B.; data curation, J.M.N. and J.M.-B.; investigation, J.M.N. and J.M.-B.; methodology, J.M.N. and J.M.-B.; resources, J.M.N.; software, J.M.N. and J.M.-B.; supervision, J.M.N.; validation, J.M.N. and J.M.-B.; writing-original draft, J.M.N. and J.M.-B.; writing-review and editing, J.M.N. and J.M.-B. All authors have read and agreed to the published version of the manuscript.

Funding: This work was supported by the Fundación Séneca del Centro de Coordinación de la Investigación de la Región de Murcia under Project 20813/PI/18.

Conflicts of Interest: The authors declare no conflict of interest.

\section{References}

1. Tang, U.; Wang, Z. Influences of urban forms on traffic-induced noise and air pollution: Results from a modelling system. Environ. Model. Softw. 2017, 22, 1750-1764. [CrossRef]

2. EC. Towards a Local Sustainability Profile: European Common Indicators; Office for Official Publications of the European Communities: Luxembourg, Luxembourg, 2000.

3. UND. World Urbanization Prospects: The 2014 Revision; United Nations Department of Economics and Social Affairs, Population Division: New York, NY, USA, 2015; p. 41.

4. Santini, S.; Ostermaier, B.; Vitaletti, A. First experiences using wireless sensor networks for noise pollution monitoring. REALWSN '08. In Proceedings of the 3rd ACM Workshop on Real-World Wireless Sensor Networks, New York, NY, USA, 2-4 April 2008; pp. 61-65.

5. Mydlarz, C.; Salamon, J.; Bello, J.P. The implementation of low-cost urban acoustic monitoring devices. Appl. Acoust. 2017 117, 207-218. [CrossRef]

6. Sodiq, A.; Baloch, A.A.; Khan, S.A.; Sezer, N.; Mahmoud, S.; Jama, M.; Abdelaal, A. Towards Modern Sustainable Cities: Review of Sustainability Principles and Trends. J. Clean. Prod. 2019, 227, 972-1001. [CrossRef]

7. Velazquez, L.; Munguia, N.; Platt, A.; Taddei, J. Sustainable university: What can be the matter? J. Clean. Prod. 2006, 14, 810-819. [CrossRef]

8. Alshuwaikhat, H.M.; Abubakar, I. An integrated approach to achieving campus sustainability: Assessment of the current campus environmental management practices. J. Clean. Prod. 2018, 36, 1777-1785. [CrossRef]

9. Disterheft, A.; Ferreira da Silva Caeiro, S.S.; Ramos, M.R.; De Miranda Azeiteiro, U.M. Environmental Management Systems (EMS) implementation processes and practices in European higher education institutions -Top-down versus participatory approaches. J. Clean. Prod. 2012, 31, 80-90. [CrossRef]

10. Lozano, R.; Young, W. Assessing sustainability in university curricula: Exploring the influence of student numbers and course credits. J. Clean. Prod. 2013, 49, 134-141. [CrossRef] 
11. Lozano, R.; Ceulemans, K.; Alonso-Almeida, M.; Huisingh, D.; Lozano, F.J.; Waas, T.; Lambrechts, W.; Lukman, R.; Hugé, J. A review of commitment and implementation of sustainable development in higher education: Results from a worldwide survey. J. Clean. Prod. 2015, 108, 1-18. [CrossRef]

12. Arya, C.; Vassie, P. Integrating sustainable development into structural design teaching. Proc. Inst. Civ. Eng. Eng. Sustain. 2015, 169, 265-276. [CrossRef]

13. Jain, S.; Pant, P. Environmental management systems for educational institutions: A case study of TERI University, New Delhi. Int. J. Sustain. High. Educ. 2010, 11, 236-249. [CrossRef]

14. Larrán, M.; Dee la Cuesta, M.; Fernández, A.; Muñoz, M.J.; López, A.; Moneva, J.M.; Rodríguez, J.M.; Martín, E.; Calzado, M.Y.; Herrera, J.; et al. Análisis del nivel de implantación de políticas de responsabilidad social en las universidades españolas. Colección Experiencias y Resultados; Conferencia de Consejos Sociales: Las Palmas de Gran Canaria, Spain, 2014; p. 3.

15. Larrán, M.; Herrara, M.; Calzado, M.Y.; Andrades, F.J. An approach to the implementation of sustainability practices in Spanish universities. J. Clean. Prod. 2015, 106, 34-44. [CrossRef]

16. Adams, M.D.; Davies, W.J.; Bruce, N.S. Soundscapes: An urban planning process map. Cult. Med. Psychiatr. 2009, 23, 273-301.

17. Goines, L.; Hagler, L. Noise pollution: A modern plague. South. Med. J. 2007, 100, 287-294. [CrossRef] [PubMed]

18. Ng, C.F. Effects of building construction noise on residents: A quasi-experiment. J. Environ. Psychol. 2000, 20, 375-385. [CrossRef]

19. Rey Gozalo, G.; Barrigón Morillas, J.M.; Montes González, D.; Atanasio Moraga, P. Relationships among satisfaction, noise perception, and use of urban green spaces. Sci. Total Environ. 2018, 624, 438-450. [CrossRef] [PubMed]

20. Lacerda, A.; Ribas, A.; Mendes, J.; Andrade, P. Noise level and its perception by commuters in urban buses of Curitiba. Can. Acoust. 2004, 32, 53-59.

21. Tristán Hernández, E.; Pavón García, I.; López Navarro, J.M.; Campos-Cantón, I.; Kolosovas-Machuca, E.S. Evaluation of psychoacoustic annoyance and perception of noise annoyance inside University facilities. Int. J. Acoust. Vib. 2018, 23, 3-8.

22. Hodgson, M.; Nosal, E.M. Effect of noise and occupancy on optimal reverberation times for speech intelligibility in classrooms. J. Acoust. Soc. Am. 2002, 111, 931-939. [CrossRef]

23. Segura-Garcia, J.; Navarro-Ruiz, J.; Perez-Solano, J.; Montoya-Belmonte, J.; Felici-Castell, S.; Cobos, M. Torres-Aranda, Spatio-Temporal Analysis of Urban Acoustic Environments with Binaural Psycho-Acoustical Considerations for IoT-Based Applications. Sensors 2018, 18, 690. [CrossRef]

24. Rauf, K.M.; Hossieni, H.; Ahmad, S.S.; Ali, H.;Kawa, H. Study of the Improvement of Noise Pollution in University of Sulaimani in both New and Old Campus. J. Pollut. Eff. Cont. 2015, 3, 1-3. [CrossRef]

25. Kang, J.; Aletta, F.; Oberman, T.; Erfanian, M.; Kachlicka, M.; Lionello, M.; Mitchell, A. Towards soundscape indices. In Proceedings of the International Congress on Acoustics-ICA, Aachen, Germany, 9-13 September 2019.

26. Sutriadi, R. Defining smart city, smart region, smart village, and technopolis as an innovative concept in indonesia's urban and regional development themes to reach sustainability. In Proceedings of the IOP Conference Series Earth and Environmental Science, Surabaya, Indonesia, 8-9 November 2018; Volume 202, pp. 12-47.

27. Zanella, A.; Bui, N.; Castellani, A.; Vangelista, L.; Zorzi, M. Internet of Things for Smart Cities. IEEE Internet Things J. 2014, 1 , 22-32. [CrossRef]

28. Wang, H.I. Constructing the green campus within the internet of things architecture. Int. J. Distrib. Sens. Netw. 2014, 10, 804627. [CrossRef]

29. Noriega-Linares, J.E.; Navarro Ruiz, J.M. On the Application of the Raspberry Pi as an Advanced Acoustic Sensor Network for Noise Monitoring. Electronics 2016, 5, 74. [CrossRef]

30. Alsina-Pagès, R.M.; Hernandez-Jayo, U.; Alías, F.; Angulo, I. Design of a Mobile Low-Cost Sensor Network Using Urban Buses for Real-Time Ubiquitous Noise Monitoring. Sensors 2017, 17, 57. [CrossRef]

31. Navarro, J.M.; Tomas-Gabarron, J.B.; Escolano, J. A big data framework for urban noise analysis and management in smart cities. Acta Acust. United Acust. 2017, 103, 552-560. [CrossRef] 
32. Stapelfeldt, H.; Manvell, D. Using dynamic noise mapping for pro-active environment noise management. In Proceedings of the International Congress on Noise Control Engineering, Inter-Noise, Osaka, Japan, 4-7 September 2011; Volume 11, pp. 4548-4556.

33. Bello, J.P.; Silva, C.; Nov, O.; Dubois, R.L.; Arora, A.; Salamon, J.; Doraiswamy, H. SONYC: A system for monitoring, analyzing, and mitigating urban noise pollution. Commun. ACM 2019, 62, 68-77. [CrossRef]

34. Alsina-Pagès, R.M.; Orga, F.; Alías, F.; Socoró, J.C. A WASN-Based Suburban Dataset for Anomalous Noise Event Detection on Dynamic Road-Traffic Noise Mapping. Sensors 2019, 19, 2480. [CrossRef]

35. Bellucci, P.; Peruzzi, L.; Zambon, G. LIFE DYNAMAP project: The case study of Rome. Appl. Acoust. 2017, 117, 193-206. [CrossRef]

36. Mietlicki, F.; Mietlicki, C.; Sineau, M. An innovative approach for long-term environmental noise measurement: RUMEUR network in the Paris region. In Proceedings of the EuroNoise 2015, Maastrich, The Netherlands, 31 May-3 June 2015.

37. Nave, L.; Mietlicki, F. Medusa, a new approach for noise management and control in urban environment. In Proceedings of the International Congress on Noise Control Engineering, Inter-Noise, Madrid, Spain, 16-19 June 2019; Volume 259, pp. 2411-2419.

38. Vinci, B.; Tonacci, A.; Caudai, C.; De Rosa, P.; Nencini, L.; Pratali, L. The SENSEable Pisa Project: Citizen-Participation in Monitoring Acoustic Climate of Mediterranean City Centers. Clean (Weinh.) 2017, 45, 1600137. [CrossRef]

39. Picaut, J.; Fortin, N.; Bocher, E.; Petit, G.; Aumond, P.; Guillaume, G. An open-science crowdsourcing approach for producing community noise maps using smartphones. Build. Environ. 2019, 148, 20-33. [CrossRef]

40. Kanjo, E. NoiseSPY: A Real-Time Mobile Phone Platform for Urban Noise Monitoring and Mapping. Mob. Netw. Appl. 2010, 15, 562-574. [CrossRef]

41. Murphy, E.; King, E.A. Testing the accuracy of smartphones and sound level meter applications for measuring environmental noise. Appl. Acoust. 2016, 106, 16-22. [CrossRef]

42. Wang, C.; Chen, G.; Dong, R.; Wang, H. Traffic noise monitoring and simulation research in Xiamen City based on the Environmental Internet of Things. Int. J. Sustain. Dev. World Ecol. 2013, 20, 248-253. [CrossRef]

43. Hakala, I.; Kivelä, I.; Ihalainen, J.; Luomala, J.; Gao, C. Design of low-cost noise measurement sensor network: Sensor function design. In Proceedings of the IEEE 1st International Conference on Sensor Device Technologies and Applications, Venice, Italy, 18-25 July 2010; pp. 172-179.

44. Sethi, S.S.; Ewers, R.M.; Jones, N.S.; Orme, C.D.L.; Picinali, L. Robust, real-time and autonomous monitoring of ecosystems with an open, low-cost, networked device. Methods Ecol. Evol. 2018, 9, 2383-2387. [CrossRef]

45. Lopez-Ballester, J.; Pastor-Aparicio, A.; Felici-Castell, S.; Segura-Garcia, J.; Cobos, M. Enabling Real-Time Computation of Psycho-acoustic Parameters in Acoustic Sensors Using Convolutional Neural Networks. IEEE Sens. J. 2020. [CrossRef]

46. Segura Garcia, J.; Pérez Solano, J.; Cobos Serrano, M.; Navarro Camba, E.; Felici Castell, S.; Soriano Asensi, A.; Montes Suay, F. Spatial statistical analysis of urban noise data from a WASN gathered by an IoT system: Application to a small city. Appl. Sci. 2016, 6, 380. [CrossRef]

47. Zamora, W.; Calafate, C.T.; Cano, J.-C.; Manzoni, P. Accurate Ambient Noise Assessment Using Smartphones. Sensors 2017, 17, 917. [CrossRef]

48. Toutouh, J.; Arellano, J.; Alba, E. BiPred: A Bilevel Evolutionary Algorithm for Prediction in Smart Mobility. Sensors 2018, 18, 4123. [CrossRef]

49. Python. Available online: https://www.python.org (accessed on 1 June 2020).

50. Margaritis, E.; Kang, J. Soundscape mapping in environmental noise management and urban planning: Case studies in two UK cities. Noise Mapp. 2017, 4, 87-103. [CrossRef]

51. Regulation (EC) of the European Parliament and of the Council of 25 June 2002 relating to the Assessment and Management of Environmental Noise-Declaration by the Commission in the Conciliation Committee on the Directive Relating to the Assessment and Management of Environmental Noise, Repealing Regulation (EC) No 49/2002. Available online: https://eur-lex.europa.eu/legal-content/EN/ALL/?uri=CELEX\% 3A32002L0049 (accessed on 3 June 2020).

52. ISO 1996-2:2017. Acoustics—Description, Measurement and Assessment of Environmental Noise—Part 2: Determination of Sound Pressure Levels; International Organization for Standardization: Geneva, Switzerland, 2017.

53. Zwicker, E.; Fastl, H. Psychoacoustics: Facts and Models; Springer: Berlin, Germany, 2013; Volume 22. 
54. ISO 532:2017. Acoustics—Methods for Calculating Loudness_Part 1: Zwicker Method; Part 2: Moore-Glasberg Method; International Organization for Standardization: Geneva, Switzerland, 2017.

55. Moore, B.C.; Glasberg, B.R. Modeling binaural loudness. J. Acoust. Soc. Am. 2007, 121, 1604-1612. [CrossRef]

56. Renz, T.; Leistner, P.; Liebl, A. Use of energy-equivalent sound pressure levels and percentile level differences to assess the impact of speech on cognitive performance and annoyance perception. Appl. Acoust. 2019, 153, 71-77. [CrossRef]

57. WHO (World Health Organization). Guidelines for Community Noise; WHO: Geneva, Switzerland, 1999. Available online: http:/ / apps.who.int/iris/handle/10665/66217 (accessed on 10 June 2020).

58. Real Decreto 1367/2007, de 19 de Octubre, por el que se Desarrolla la Ley 37/2003, de 17 de Noviembre, del Ruido, en lo Referente a Zonificación Acústica, Objetivos de Calidad y Emisiones Acústicas. Available online: https: / www.boe.es/buscar/pdf/2007/BOE-A-2007-18397-consolidado.pdf (accessed on 7 March 2019).

(C) 2020 by the authors. Licensee MDPI, Basel, Switzerland. This article is an open access article distributed under the terms and conditions of the Creative Commons Attribution (CC BY) license (http:/ / creativecommons.org/licenses/by/4.0/). 